\title{
DIMENSIÓN TERRITORIAL Y TURÍSTICA DE LA RUTA NORTE DEL CAMINO DE SANTIAGO EN EL PAIIS VASCO: DISTINTAS CONCEPCIONES, VALORACIONES Y PROPUESTAS DE INTERVENCIÓN SOBRE UN FENÓMENO MULTIFACÉTICO'
}

\author{
María Cruz Porcal Gonzalo, Adrián Díez Angulo y Josu Junguitu Iñiguez de Heredia \\ Departamento de Geografía, Prehistoria y Arqueología. Universidad del País Vasco
}

\section{RESUMEN}

El Camino de Santiago constituye un fenómeno multifacético de proyección y reconocimiento internacional: forma parte del patrimonio cultural intangible, pero también es una secular ruta de peregrinación, un elemento territorial de alto valor simbólico y un producto turístico de prestigio. El objetivo primordial de este trabajo consiste en evaluar las características y la incidencia de la ruta norte del Camino de Santiago en el País Vasco, uno de los itinerarios que cada vez más se está perfilando como alternativa al Camino Francés. Se hace hincapié en su dimensión territorial y turística y, particularmente, en la imagen y valoración que sobre el mismo tienen los principales colectivos y agentes sociales implicados en él. Con dicho afán, se presenta el marco territorial y la infraestructura turística que articula el recorrido así como los caracteres más destacados de la demanda, prestándose una atención

Fecha de recepción: julio 2010.

Fecha de aceptación: febrero 2012

1 Este trabajo se inscribe en el Proyecto de Investigación Terciarización de las montañas en la Comunidad Autónoma Vasca y en Navarra: procesos de desarrollo turístico y sostenibilidad territorial (EHU08/60) financiado por la Universidad del País Vasco (U.P.V./E.H.U.), cuya investigadora principal es Dra. M ${ }^{\mathrm{a}}$ Cruz Porcal Gonzalo y, asimismo, en el convenio de colaboración establecido entre la Universidad del País Vasco e IDEGA-Universidad de Santiago de Compostela (T5402) en el marco del Estudio sobre el Producto Turístico Camino de Santiago en el horizonte del año jacobeo 2010 financiado por Turespaña (Ministerio de Industria, Turismo y Comercio) y liderado por Dr. Xosé Santos. Ha contado además con el patrocinio y apoyo financiero otorgado por el Departamento de Educación, Universidades e Investigación del Gobierno Vasco al Grupo Consolidado de Investigación en Patrimonio y Paisajes Culturales IT315-10. 
prioritaria a los peregrinos extranjeros. Tras la realización de 195 encuestas y entrevistas y de un amplio trabajo de campo se identifican las primordiales concepciones y visiones existentes acerca del Camino y se llega a un diagnóstico global sobre sus oportunidades, fortalezas, amenazas y debilidades, a partir del cual se proponen unas líneas de actuación.

Palabras clave: Patrimonio Cultural, Desarrollo turístico, Peregrinaciones, Ruta Norte del Camino de Santiago, País Vasco.

\begin{abstract}
The Way of Saint James (which from hereon we shall refer to in the original Spanish -Camino de Santiago) is a multifaceted phenomenon, internationally projected and recognised: it forms part of an intangible cultural heritage but is also a centuries old route for pilgrimage, a territorial element which is symbolically highly valuable and a prestigious touristic product. The primary objective of this study is to evaluate the characteristics and impact of the Ruta Norte (northern route) of the Camino de Santiago in the Basque Country, one of the itineraries that is increasingly becoming more popular as an alternative to the Camino Frances (the French way). Emphasis is placed on the territorial and touristic dimension and, in particular, on the image the main groups involved have of the Camino and how they value it. With this as our aim, the territorial framework and touristic infrastructure which articulate the route will be presented, as well as the main characters that comprise the demand for the route, with foreign pilgrims being paid special attention. After carrying out 195 surveys and interviews and extensive field work the main concepts and visions that people have of the Camino have been identified and the existing opportunities, threats, strengths and weaknesses have been comprehensively diagnosed with the resultant proposals for courses of action.
\end{abstract}

Key words: Cultural heritage, Tourist development, Pilgrimages, «Ruta Norte» of the Way of Saint James, Basque Country.

\title{
I. INTRODUCCIÓN: EL CAMINO DE SANTIAGO, UN FENÓMENO MULTIFACÉTICO
}

Como es sobradamente conocido, el Camino de Santiago constituye un fenómeno multifacético profundamente arraigado en Europa. Un fenómeno que ha dado pie a la publicación de un amplio elenco de libros y revistas abordados desde perspectivas dispares, a la celebración de numerosos congresos, cursos y conferencias nacionales e internacionales, al desarrollo de trabajos de investigación, a la creación de cátedras universitarias, etc.

En primer lugar, se trata de un referente cultural de primer orden, de lo que dan buena fe las numerosas calificaciones otorgadas al respecto: Primer Itinerario Cultural Europeo (Consejo de Europa, 1987), Patrimonio de la Humanidad (UNESCO, 1993), Tesoro del Patrimonio Cultural Inmaterial de España (Bureau Internacional de Capitales Culturales, 2009), Bien Cultural con la categoría de Conjunto Monumental (Decreto 14/2000, Ley 
de Patrimonio Cultural Vasco). ${ }^{2}$ Cabe recordar que el término patrimonio, aunque ha sido objeto de diversas acepciones, a grandes rasgos hace referencia al conjunto de elementos naturales o culturales con que cuenta un determinado territorio o grupo humano y que son considerados valiosos por parte de la sociedad, de ahí que sea un concepto cuya singularidad radica en la existencia de ese reconocimiento y valoración social. Evidentemente que el Camino de Santiago fuera declarado por la UNESCO Patrimonio de la Humanidad garantiza que es poseedor de un valor universal excepcional que trasciende fronteras pero, a su vez, pone en resalte su fragilidad, la necesidad de su conservación y, en suma, el compromiso asumido a escala mundial de amparo, protección, mantenimiento y rehabilitación. Como bien patrimonial, pertenece al patrimonio cultural y, dentro de él, al patrimonio cultural intangible o inmaterial; más concretamente, se trata de un Itinerario Cultural, lo cual le confiere unos rasgos singulares. La categoría de patrimonio cultural inmaterial implica que forma parte del conjunto de «usos, representaciones, expresiones, conocimientos y técnicas...que las comunidades, los grupos y los individuos reconocen como parte integrante de su patrimonio cultural...., los cuales se ponen de manifiesto en ámbitos diversos» (art. 2 de la Convención para la Salvaguardia del Patrimonio Cultural Inmaterial, UNESCO, 2003); así pues, es un bien intangible cuyo alto contenido simbólico le hace merecedor de una especial protección. En tanto Itinerario Cultural constituye una ruta de comunicación físicamente delimitada, de fuerte significado histórico y carácter dinámico, que acoge un movimiento continuo de personas y que ha sido y sigue siendo testigo de un intercambio recíproco de ideas, conocimientos y valores entre gentes, continentes, países o regiones, durante un significativo periodo de tiempo (ICOMOS, 2008; UNESCO, 2008). A su vez, como parte integrante del Programa de Itinerarios Culturales del Consejo de Europa se considera que el Camino de Santiago posee un papel estratégico para la construcción de una identidad europea, en la medida en que puede hacer más visible y más viva en la vida cotidiana, la identidad cultural común de los ciudadanos de dicho ámbito. También se pone el acento en su capacidad para contribuir a conservar y revalorizar el patrimonio cultural (Tondre, 2007). Por consiguiente, desde esta perspectiva el Camino de Santiago es para muchos, prioritariamente, un lugar de encuentro y de intercambio de vivencias entre personas de nacionalidades diversas, un espacio de «formación»e «información» que entronca con su carácter de itinerario cultural.

En segundo lugar, posee una indiscutible vertiente religiosa y espiritual en tanto en cuanto se trata de una ruta de peregrinación. Según el Diccionario de la R.A.E. peregrinar es ir en romería a un santuario por devoción o por voto mientras que se denomina peregrino a aquella persona que realiza esa ruta. Así pues, toda peregrinación puede ser entendida como un viaje motivado por cuestiones religiosas y realizado por una persona creyente a un espacio considerado sagrado en virtud de su magnetismo espiritual (Porcal, 2006). Ciertamente, constituye un fenómeno colectivo pero de naturaleza individual, percibido y vivido de diversas maneras. Ahora bien, como se irá comprobando a lo largo del trabajo, las moti-

2 Cumple, al menos, dos de los seis requisitos exigidos para que un bien cultural sea declarado Patrimonio de la Humanidad: a) Ser la manifestación de un intercambio considerable de valores humanos durante un determinado período o en un área cultural específica, en el desarrollo de la arquitectura, las artes monumentales, la planificación urbana o el diseño paisajístico; b) Estar directa y perceptiblemente asociado con acontecimientos o tradiciones vivas, ideas o creencias de importancia o de significado universal excepcional. 
vaciones que en la actualidad inducen a emprender el Camino de Santiago no son siempre estrictamente religiosas ni tampoco espirituales sino que, a menudo, conviven con aspiraciones de ocio vacacional. Se advierte que el peso de unas y otras en el proceso de decisión ha cambiado a lo largo de la historia al compás, por ejemplo, de las corrientes de pensamiento y de la mayor o menor secularización de la sociedad.

Por su parte, su dimensión territorial se manifiesta en un amplio abanico de aspectos. El Camino de Santiago es un itinerario cultural que se ha ido acomodando a los caracteres geográficos de los territorios preexistentes al tiempo que, secularmente, ha dejado su impronta en ellos, gracias al trasiego de ideas, estilos arquitectónicos, urbanísticos, etc. que ha permitido. Asimismo, como toda ruta, adquiere su razón de ser en la medida en que implica un desplazamiento en el espacio desde un punto de origen (el lugar de residencia) hasta un destino (el santuario-catedral de Santiago de Compostela). Sin embargo, en este caso, el viaje cobra tanto o más protagonismo que la experiencia en el destino, lo que lo convierte en una práctica social genuinamente territorial. Por otra parte, hay que tener presente que el paisaje - entendido como patrimonio territorial y escenario visible y percibido de la organización funcional del hombre con el medio - constituye para muchos peregrinos uno de los atractivos más destacados a lo largo del recorrido. En otro orden de cosas, el Camino de Santiago está llamado a desempeñar un significativo papel como instrumento de articulación, cooperación y cohesión territorial, tal y como ya se ha hecho patente mediante la firma de distintos convenios y acuerdos de carácter interregional para su planificación, promoción y gestión.

Pero, evidentemente, el Camino de Santiago no es sólo un patrimonio cultural intangible, una ruta de peregrinación y un elemento territorial de alto valor simbólico sino que, desde tiempo atrás, ha sido objeto de uso turístico, el cual se ha revitalizado en los últimos años. Más concretamente, se evidencia que en España ha experimentado un importante auge a raíz del Jacobeo de 1993 (Santos, 1999; Lois y Santos, 1999). Así pues, en nuestros días la ruta jacobea es un producto turístico promocionado y comercializado por las instituciones públicas y también por las empresas privadas mediante distintos cauces de difusión (por ejemplo, agencias de viajes) y estrategias de marketing (publicaciones, guías, folletos, páginas webs, etc.). Sin lugar a dudas, constituye una marca turística de éxito e internacionalmente conocida y, a su vez, de prestigio, por el valor que supone hallarse incluido en la lista de bienes Patrimonio de la Humanidad. En razón de su mencionado carácter poliédrico, el Camino de Santiago supone un exponente del turismo cultural pero también del turismo religioso y de peregrinaciones, unos términos cuyo contenidos y contornos difusos han generado reflexiones e interpretaciones conceptuales distintas (Turner y Turner, 1978; Aucort, 1990; Vukonic, 1997; Eade, 2002; Porcal 2006). En este contexto de complejidad conceptual, resulta ilustrativa la clasificación definida por Smith (1992) para diferenciar turismo y peregrinaje y acertada - a nuestro entender - la adopción de la intensidad de la motivación religiosa en el viaje como criterio de discriminación. De este modo, turistas y peregrinos son considerados los polos opuestos de una gradación: un extremo lo ocupa el peregrino piadoso que realiza una peregrinación basada en la fe, el otro, el turista estrictamente secular. En una posición intermedia se sitúa el turista religioso, quien a su vez puede ser, según predomine en mayor o menor grado la fe o lo profano en sus motivaciones y actividades, un viajero más peregrino que turista, un viajero tan peregrino como turista o un viajero más turista que peregrino. En 
concordancia con todo ello, Santiago de Compostela se revela como un espacio multifuncional; un lugar de peregrinación y de visita turística.

El auge experimentado por el turismo cultural y también por el turismo religioso es preciso enmarcarlo en el contexto de un uso más activo del tiempo libre y de diversificación de productos turísticos para satisfacer a una demanda cada vez más exigente y variada. Se estima que en el año 2006 alrededor de 150 millones de peregrinos viajaron por el mundo. Por su parte, la Basílica de Compostela constituye el principal destino de peregrinación con proyección internacional de España, con una media de 4 millones de visitantes al año, de los cuales algo más de 100.300 fueron en el 2006 peregrinos (Germain, 2007), un número que en el 2009 ascendió a 145.877. Estos datos evidentemente aumentan de forma exponencial en los años jubilares. Así, según las previsiones de la Xunta de Galicia en el presente Año Santo 2010 serán 9 millones los visitantes por dicho motivo. Todas estas cifras y la creciente atención otorgada al turismo religioso por parte de la O.M.T. (Conferencia Internacional de Turismo, Religiones y Diálogo entre culturas, Quito 2006; Córdoba, 2007) parecen constatar que se trata de un sector en alza.

Su condición de producto turístico, que lleva asociados numerosos servicios, hace que sea también un fenómeno económico que genera rentas y empleos así como un instrumento de desarrollo regional capaz de revitalizar los lugares que atraviesa (Santos, 1999; Precedo, 2007). En todo caso, hay que decir que a menudo resulta difícil cuantificar los efectos atendiendo al último aspecto. Con ello entronca, a su vez, la creciente atención dispensada al Camino por parte de numerosas instituciones y organismos públicos y privados. Dicha atención queda asimismo refrendada en su incorporación a distintos instrumentos de planificación; el inicio del procedimiento de aprobación del Plan Regional de Ámbito Territorial del Camino de Santiago en Castilla y León, según la Resolución de 25 de mayo de 2010, constituye tan sólo un ejemplo de ello.

\section{OBJETIVOS Y METODOLOGÍA}

En el País Vasco el sector turístico - aunque con oscilaciones - ha mantenido una tendencia ascendente en los últimos años hasta representar actualmente el 5,2\% del P.I.B. del País Vasco y el 4,9\% del empleo, unas proporciones todavía modestas pero con capacidad de crecimiento. En este contexto el turismo religioso ha manifestado un comportamiento positivo. En el marco de los productos turísticos incluidos en el I Plan de Marketing del Turismo Vasco, Hor Dago! Plana, 2009-2012 y, más concretamente, de los que en nuestros días se están ofertando en el mercado nacional e internacional, el Camino de Santiago se halla catalogado como un producto «A» con un alto valor potencial.

Al igual que en el conjunto de Europa, en el País Vasco cabe hablar, más que del Camino, de los Caminos de Santiago. Como se expondrá a lo largo del trabajo, dos rutas jalonadas de albergues y de elementos patrimoniales atraviesan el territorio vasco hacia el mismo destino: por un lado, el Camino Francés que, atendiendo a la superficie ocupada, posee en el País Vasco una importancia inferior a la alcanzada en otros territorios vecinos (Navarra, La Rioja y Burgos); por otro lado, el Camino del Norte que tiene en el País Vasco su puerta de entrada en España y que recorre la accidentada costa guipuzcoana y vizcaína. Este último se ha revitalizado considerablemente en los últimos años convirtiéndose en uno de los prin- 
cipales protagonistas de la promoción turística internacional de la España Verde (una marca integrada por las comunidades autónomas de Galicia, Asturias, Cantabria y País Vasco). Así pues, aunque hunde sus raíces en el pasado, el Camino del Norte constituye una alternativa contemporánea al Camino Francés (con el que, por otro lado, mantiene fuertes conexiones) impulsada por intereses de promoción turística. Ante ello, parece factible plantear como hipótesis inicial que su interpretación y valoración actual se hallen en gran medida condicionadas por la imagen espacial de reconstrucción histórica utilizada esencialmente con fines publicitarios y comerciales.

En el presente trabajo se parte de la convicción de que la comprensión, planificación y gestión de un fenómeno poliédrico como el Camino de Santiago exige una visión integral. Se hará hincapié en su dimensión territorial y turística y, particularmente, en la concepción y valoración que sobre el mismo tienen los principales usuarios y agentes implicados, con el objetivo primordial de conocer la incidencia del Camino de Santiago en el País Vasco. Hay que decir que se ha optado por centrar la investigación, desde el punto de vista territorial, en el Camino Norte - menos estudiado - y, desde el punto de vista turístico esencialmente en la demanda y, dentro de ella, en los peregrinos extranjeros, que nos van a permitir atisbar el nivel de proyección internacional de dicho patrimonio. Atendiendo a la información proporcionada por la Federación Española de Asociaciones de Amigos del Camino de Santiago, la ruta del Norte registró 17.582 pernoctaciones en albergues durante el año 2009, una cifra que casi se ha triplicado en apenas tres años (6.697 en el 2006, 9.712 en el 2007 y 14.204 en el 2008). Asimismo se estima que acogió un volumen total de peregrinos de 5.378 en el año 2006 y 7.035 en el año 2008 , representando el 5,2 \% y 5,6 \% respectivamente de todos los contabilizados en el conjunto de itinerarios jacobeos, lo que le sitúa en el tercer puesto tras el Camino Francés $(82,1 \%$ y $78,9 \%)$ y el Portugués $(6,4 \%$ y $7,8 \%)$.

En virtud de su carácter de producto turístico, se presentará el marco territorial en el que éste se integra y se analizará la infraestructura básica que articula el recorrido (red de alojamientos, servicios de restauración, oficinas de información) así como la demanda existente. Ello significa que de los tres elementos clave de un sistema de peregrinación, el viaje, los peregrinos y el santuario (Morinis, 1992), se incidirá en los dos primeros. Se prestará una particular atención a la valoración efectuada por esos protagonistas del viaje pero también a la realizada por responsables de instituciones variadas. Se sintetizarán las principales concepciones e interpretaciones existentes sobre dicha ruta, una pluralidad de visiones que resulta conveniente tener en cuenta para establecer de forma consensuada procesos de planificación y gestión eficaces y capaces de resolver la compleja relación patrimonio-turismo. Todo ello, sumado a la valoración propia y al conocimiento del territorio objeto de estudio, permitirá llegar a un diagnóstico global sobre las fortalezas, debilidades, amenazas y oportunidades que, en los albores del Año Santo Jacobeo 2010, presenta el Camino Norte.

Para alcanzar esos fines se ha utilizado una metodología sustentada prioritariamente en la realización de encuestas, entrevistas y en un vasto trabajo de campo. Así se han efectuado un total de 195 encuestas y entrevistas en distintos puntos del Camino dirigidas a los siguientes colectivos: peregrinos extranjeros que realizan la ruta jacobea, empresarios que componen la oferta básica o complementaria a lo largo de ella, responsables de instituciones culturales, 
turoperadores y agencias de viajes, y técnicos-expertos de la Comunidad Autónoma del País Vasco $^{3}$.

Más concretamente, se han llevado a cabo 100 encuestas a peregrinos extranjeros (64 en inglés, 31 en francés y 5 en castellano), atendiendo un plan previo de distribución espacial y temporal. Las encuestas se han realizado en albergues de peregrinos, mayoritariamente en los dependientes de las Asociaciones de Amigos del Camino de Santiago, durante los meses de Junio y Julio del 2009, siguiendo el criterio general de ir remontando el Camino de Oeste a Este para evitar el riesgo de encuestar a las mismas personas en más de una ocasión. Asimismo se ha efectuado un número mayor de encuestas en Vizcaya que en Guipúzcoa teniendo en cuenta que, en la primera, los peregrinos cuentan con un registro superior de días de viaje y, por ello, con una experiencia más dilatada para diagnosticar mejor esta ruta norte.

Tabla 1

DISTRIBUCIÓN ESPACIAL DE LAS ENCUESTAS REALIZADAS A LOS PEREGRINOS EXTRANJEROS

\begin{tabular}{|l|l|c|}
\hline \multicolumn{1}{|c|}{ Nombre } & \multicolumn{1}{|c|}{ Institución responsable } & $\begin{array}{c}\mathbf{N}^{\mathbf{0}} \\
\text { encuestas }\end{array}$ \\
\hline GUIPÚZCOA & & $\mathbf{3 1}$ \\
\hline Albergue de Peregrinos de Irún & $\begin{array}{l}\text { Asociación de Amigos del Camino de } \\
\text { Santiago de Gipuzkoa }\end{array}$ & 4 \\
\hline Albergue de Peregrinos de Orio & Privada & 10 \\
\hline Albergue de Peregrinos de Deba & $\begin{array}{l}\text { Asociación de Amigos del Camino de } \\
\text { Santiago de Gipuzkoa }\end{array}$ & 17 \\
\hline VIZCAYA & & $\mathbf{6 9}$ \\
\hline $\begin{array}{l}\text { Albergue de Peregrinos de Markina- } \\
\text { Xemein }\end{array}$ & $\begin{array}{l}\text { Asociación de Amigos del Camino de } \\
\text { Santiago de Bizkaia }\end{array}$ & 25 \\
\hline Albergue de Peregrinos de Lezama & $\begin{array}{l}\text { Asociación de Amigos del Camino de } \\
\text { Santiago de Bizkaia }\end{array}$ & 19 \\
\hline Albergue de Peregrinos de Pobeña & $\begin{array}{l}\text { Asociación de Amigos del Camino de } \\
\text { Santiago de Bizkaia }\end{array}$ & 25 \\
\hline
\end{tabular}

La distribución de los porcentajes de peregrinos encuestados se ha establecido atendiendo a su procedencia, ajustándose a los datos proporcionados a este respecto por la red de albergues de la ruta norte del País Vasco, según los cuales existe una gran diversidad pero Alemania y Francia, dentro de Europa, y Estados Unidos y Canadá, en el resto del mundo, son los principales países emisores aglutinando algo más de las tres cuartas partes de ellos (el $62 \%$ ). Por lo que se refiere al tipo de encuesta se han aplicado encuestas personales mediante un cuestionario estructurado. A partir de ellas, se han definido el perfil, las motivaciones, los

3 El número total de encuestas vino definido por la metodología general establecida para el conjunto de España en el marco del Estudio sobre el Producto Turístico Camino de Santiago en el horizonte del año jacobeo 2010 (tamaño muestral global de 2.232 encuestas para un nivel de confianza del $95 \%$ y un tipo de muestreo por cuotas estructurado por Comunidades Autónomas). 
hábitos y los comportamientos de dichos peregrinos y también su percepción y valoración acerca de distintos elementos del Camino.

A su vez, y tras la confección previa de un inventario completo de empresas y servicios vinculados de algún modo al Camino de Santiago, se han realizado 53 encuestas a responsables de los mismos. Para la elaboración de dicho inventario han sido empleadas fuentes variadas así como la información suministrada al respecto por el personal de las Asociaciones de Amigos del Camino de Santiago. A la hora de elegir los sujetos de encuesta se ha tratado de que hubiera diversidad atendiendo tanto al tipo de empresa como al ámbito territorial escogido, para evitar una representación sesgada en este sentido. Como resultado de ello, han sido encuestados los responsables de todos los albergues dependientes de las Asociaciones de Amigos del Camino de Santiago al ser éstos los servicios de alojamiento más demandados por los peregrinos; pero también se han dirigido a albergues privados, albergues públicos situados en las inmediaciones del Camino y a empresas (pensiones, hoteles, casas rurales, agroturismos, campings, bares y restaurantes) que guardan algún tipo de relación con el Camino, en tanto en cuento los peregrinos forman parte — en mayor o menor medida - de su clientela. Por medio de estas encuestas se ha pretendido conocer los impactos del Camino de Santiago, en particular desde el punto de vista económico y social, los niveles de ocupación de los servicios ofertados, las ayudas y subvenciones recibidas, la imagen percibida así como las perspectivas de futuro atendiendo a unos y otros aspectos.

Por otra parte - y también una vez realizado el inventario correspondiente - se han llevado a cabo 30 encuestas dirigidas a responsables de instituciones, organismos y entidades culturales. De este amplio colectivo han sido seleccionadas las Asociaciones provinciales de Amigos del Camino y sus delegaciones comarcales, las oficinas de turismo y puntos de información turística ubicados en lugares por donde pasa la ruta jacobea, algunos museos y Centros de Interpretación (escogiéndose aquéllos en los que se ha constatado una afluencia de peregrinos o los que se ha considerado que, por su características, son más proclives a recibirla en el futuro) y otras instituciones ligadas al desarrollo del turismo en municipios o comarcas. Por consiguiente, se trata de un grupo extenso y heterogéneo pero unido por su vinculación a la gestión o difusión del patrimonio relacionado con el Camino así como por un fin sustancialmente de carácter social. Las preguntas que han estructurado las encuestas se han encaminado en este caso a definir las características básicas de cada institución, las medidas de gestión empleadas (por ejemplo, para establecer la capacidad de carga), la oferta de servicios, la demanda existente al respecto y su grado de satisfacción, las estrategias de marketing implementadas, las tendencias detectadas y las expectativas de crecimiento del Camino de Santiago.

Por lo que se refiere a las encuestas dirigidas al colectivo de agencias de viaje el procedimiento de trabajo ha sido el siguiente: se ha creado previamente una base de datos digital estructurada desde el punto de vista territorial y de acuerdo a una tipología establecida (turoperadores y mayoristas, minoristas y agencias de receptivo); se ha llevado a cabo la selección de aquéllas que comercializan el producto turístico «Camino de Santiago»; y, por último, se han visitado personalmente 10 de ellas. Se han abordado aspectos tales como las características de dicho producto, el perfil de sus clientes, los servicios más demandados, su evolución, el modo o estrategias de comercialización y promoción, etc. 
Este espectro de encuestas se ha completado con dos entrevistas efectuadas a un técnicos de la Administración Regional, expertos en cuestiones turísticas, con el afán último de conocer su valoración sobre diversos aspectos vinculados prioritariamente a la gestión del Camino de Santiago.

Tras la ejecución de las encuestas y — como suele ser habitual en estos casos - se ha procedido al volcado de datos en el ordenador y a la organización y tratamiento de los mismos mediante el programa informático SPSS. Pero, tan importante como las encuestas y entrevistas, ha sido el trabajo de campo efectuado, el cual ha resultado crucial para comprender verdaderamente la dimensión territorial del Camino de Santiago y para detectar sus debilidades y fortalezas en tanto producto turístico.

\section{LA DIMENSIÓN TERRITORIAL DEL CAMINO DE SANTIAGO}

Cabe afirmar que el Camino de Santiago constituye un fenómeno íntimamente ligado al medio físico y humano de las regiones que atraviesa, siendo, a su vez, testigo y depositario de un sinfín de avatares históricos que, desde tiempos muy remotos, han regido el devenir de las sociedades que para él y en torno a él han vivido. Se trata también de una vía relicta, de sinuoso y accidentado trazado, que tuvo que adaptarse forzosamente a las características del relieve y, asimismo, buscar la ruta más adecuada en función de la distribución del poblamiento y, sobre todo, de la localización de los principales hitos religiosos. Todo esto se hace sentir muy notablemente en el ámbito de este estudio, el País Vasco, donde la ruta jacobea se encuentra con una orografía sumamente intrincada, un poblamiento articulado en ciudades, pueblos y caseríos, y una sociedad construida sobre identidades y creencias muy marcadas. No puede obviarse, por lo tanto, la evidente dimensión geográfica y territorial que atesora el Camino de Santiago en su tramo vasco, la cual sumada a los tradicionales méritos de conservación de esta ruta (valor de su patrimonio histórico-arquitectónico, etc.), le convierten en un fenómeno altamente valioso y singular. Ciertamente, el Camino se traduce en una amplia gama de escenas visuales donde numerosos bienes patrimoniales quedan integrados formando un todo. En razón de ello, cabe ser considerado como uno de los principales ejes del «paisaje cultural» vasco o - tal y como reza el Convenio Europeo del Paisaje aprobado en el año $2000-$ del «paisaje» sin adjetivos.

\section{Los «Caminos de Santiago»: las dos rutas}

Como se ha avanzado, dos son los itinerarios jacobeos que atraviesan el País Vasco. Por un lado, el Camino del Norte que, con una dirección general E-O, discurre paralelo a la costa desde Irún (Guipúzcoa) hasta Covarón (Vizcaya) a lo largo de aproximadamente 171 kms. En dicha localidad guipuzcoana también da comienzo la segunda vía, el Camino Vasco de Interior, cuyo trazado atraviesa en sentido NE-SO las provincias de Guipúzcoa y Álava para, finalmente, enlazar con el Camino Francés en Santo Domingo de la Calzada (La Rioja). A través del valle del Oria, del túnel de San Adrián - que traspasa la sierra de Aitzgorri-, de la Llanada Alavesa y de la cuenca de Treviño esta ruta suma un total de $201 \mathrm{kms}$. En el tramo guipuzcoano existe una variante conocida como «camino de Saiatz», que avanza por enclaves montañosos (macizo del Ernio) paralelamente al valle del Oria, a unos pocos kiló- 
metros al oeste de él, hasta confluir con la ruta tradicional en las inmediaciones de la villa de Segura (perteneciente a la comarca del Goierri). Así pues, mientras el Camino del Norte representa una alternativa íntegra al Camino Francés, en tanto en cuanto llega a tierras gallegas, el Camino Vasco de Interior funciona como un afluente de este último, acogiendo a los peregrinos extranjeros o vascos que pretenden enlazar con él.

\section{El Camino del Norte: un trazado exigente, atlántico y costero}

Este trabajo de investigación se ha centrado en el tramo del Camino Norte que recorre la Comunidad Autónoma del País Vasco (Fig. 1). Como se ha señalado, sus puntos de inicio y final son, respectivamente, Irún (UTM: X=598598; Y=4800535) y Covarón (UTM: $\mathrm{X}=487792$; $\mathrm{Y}=4799987$ ). La ruta se inscribe íntegramente en los valles cantábricos vascos y, por consiguiente, en la región bioclimática atlántica. Su trazado discurre en sentido zonal (esto es, E-O) perpendicularmente, por lo tanto, a los principales ríos que, con una dirección principal N-S, configuran el territorio (Bidasoa, Oiartzun, Urumea, Oria, Urola, Deba, Artibai, Lea, Oka, Ibaizabal y Barbadún). Ello permite entender que el Camino se vea obligado a superar un considerable número de interfluvios que, en todo caso, rara vez rebasan los $500 \mathrm{~m}$. Asimismo explica la sinuosidad del recorrido y, sobre todo, sus fuertes pendientes, máxime teniendo en cuenta la proximidad al mar; los tramos llanos escasean y los desniveles relativos de altitud acumulados en cada etapa llegan, en algunos casos, a sobrepasar los 1.000 metros, lo que pone de manifiesto el intenso esfuerzo físico que requiere completar esta ruta. A este respecto, la cota máxima se localiza en el monte Jaizkibel (543 m.), mientras que la mínima no es otra que el nivel del mar, el cual se alcanza en repetidas ocasiones.

El itinerario atraviesa, de E a O, las comarcas guipuzcoanas del Bajo Bidasoa, DonostiaSan Sebastián, Urola Costa y Bajo Deba, siendo Irún, Hondarribia, Pasajes, Donostia-San Sebastián, Orio, Zarautz, Zumaia y Deba las localidades más destacables en dicho recorrido. Por su parte, en el tramo vizcaíno el Camino transcurre por las comarcas de Markina-Ondarroa, Gernika-Bermeo y Gran Bilbao; Markina, Gernika, Bilbao y Portugalete constituyen, en este caso, los núcleos principales. Las densidades de población presentan una gran disparidad, con algunas comarcas eminentemente urbanas tales como el Gran Bilbao (2.468,9 hab./ $\mathrm{km}^{2}$ en el año 2009) o Donostia-San Sebastián (1.050,5 hab./ $\left.\mathrm{km}^{2}\right)$, y otras de carácter más rural (Markina-Ondarroa con 129,1 hab./km², o Gernika-Bermeo, con 161,2 hab./km²). Por su parte, el hábitat varía desde la dispersión protagonizada por las zonas de caserío hasta las elevadas concentraciones de población que albergan ciudades como Bilbao y DonostiaSan Sebastián (354.860 y 180.761 habitantes respectivamente en el año 2009).

Como consecuencia de lo anteriormente señalado, el viajero va descubriendo a lo largo del Camino Norte un rico mosaico de paisajes rurales, rururbanos e incluso metropolitanos, con un neto predominio de los primeros, siempre en un contexto bioclimático oceánico. $\mathrm{He}$ aquí algunos de sus rasgos: abundancia de lluvias y ausencia de estación seca, veranos e inviernos suaves y unos valores medios anuales que, por lo que se refiere a las temperaturas, habitualmente rondan $\operatorname{los} 14^{\circ} \mathrm{C} \mathrm{y}$, en cuanto a las precipitaciones, los 1.100-1.700 mm. Así pues, en el ámbito rural, las coberturas de suelo predominantes son los prados y el policultivo propios de la campiña atlántica, los pastos, las repoblaciones forestales de coníferas 


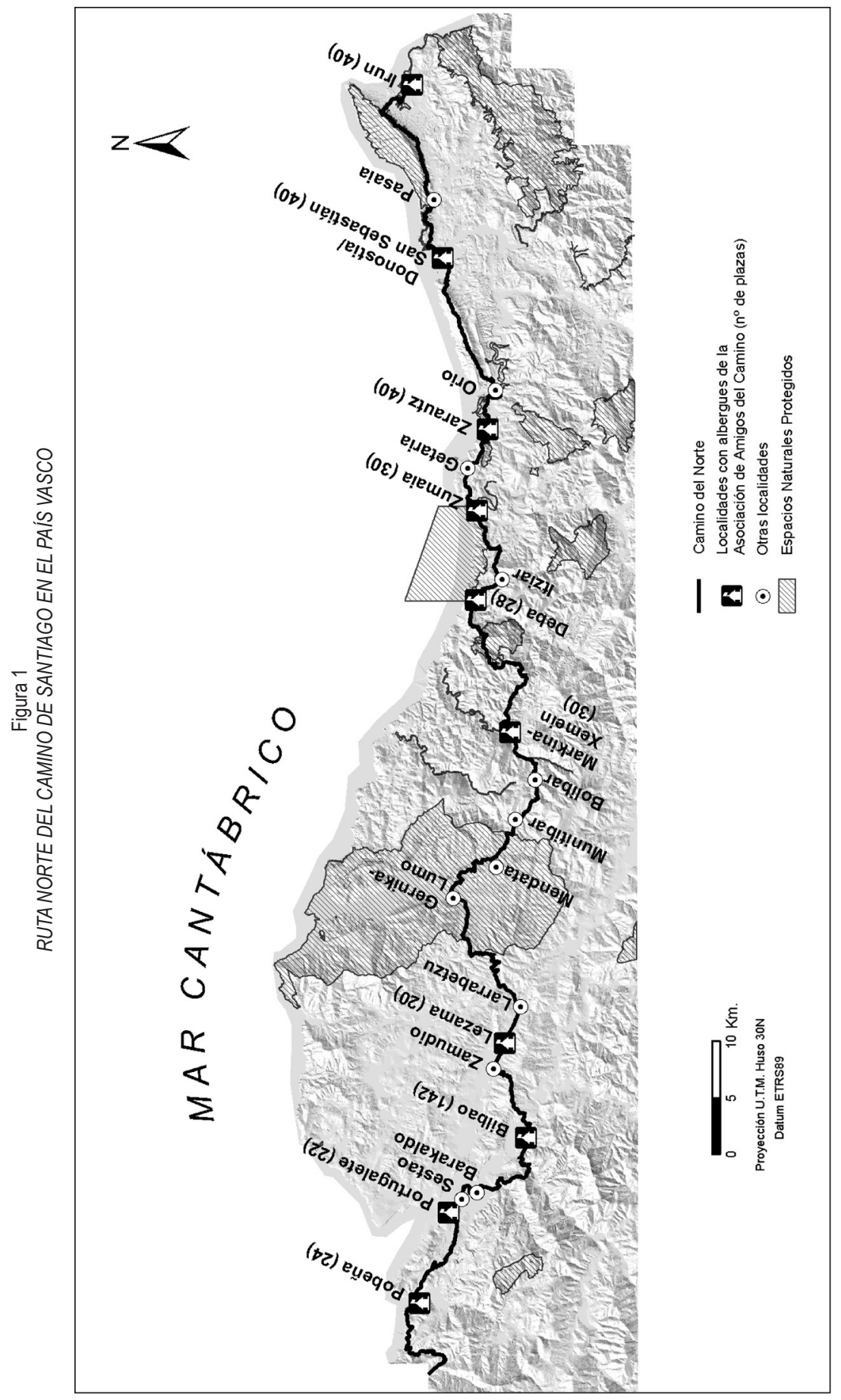

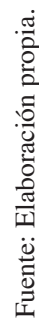


exóticas (Pinus insignis) y las esporádicas manchas de frondosas autóctonas (Quercus robur, Castanea sativa, $Q$. ilex, etc.). Estas ocupaciones de suelo corresponden mayoritariamente a propiedad privada la cual, en el conjunto de municipios por los que discurre la ruta jacobea, supone el 89,4\% frente al 10,6\% que equivale la propiedad comunal. En suma, las tipologías de paisajes predominantes están representadas por paisajes ganaderos y forestales atlánticos de fuertes matices verdes, por paisajes litorales de tradicional uso pesquero y turístico, y por paisajes ligados a la expansión de una ciudad rectora caracterizados por la mezcla de usos y actividades.

En cuanto al patrimonio natural que atesora el Camino del Norte, resulta significativo resaltar la gran cantidad de espacios protegidos por los que éste transcurre: 11 Lugares de Importancia Comunitaria (LIC), 1 Biotopo Protegido (BP) y 1 espacio singular declarado, a la vez, Reserva de la Biosfera, Zona de Especial Protección para las Aves y LIC. Enumerados de Este a Oeste son los siguientes: Txingudi-Bidasoa (LIC), Jaizkibel (LIC), Ulia (LIC), Ría del Oria (LIC), Inurritza (LIC), Garate-Santa Bárbara (LIC), Ría del Urola (LIC), tramo litoral Deba-Zumaia (Biotopo Protegido), Arno (LIC), Río Artibai (LIC), Río Lea (LIC), Urdaibai (Reserva de la Biosfera, Zona de Especial Protección para las Aves y LIC) y Ría del Barbadun (LIC). Por su parte, el patrimonio cultural destaca por su riqueza y variedad, albergando bienes de todo tipo tales como monumentos prehistóricos (Jaizkibel, Igeldo, cueva de Ekain, etc.), iglesias y catedrales (catedral de Santiago de Bilbao, iglesia de San Pedro en Zumaia, etc.), colegiatas y santuarios (Zenarrutza en Ziortza-Bolibar, Guadalupe en Hondarribia, etc.), ermitas (San Telmo en Zumaia, Santa Bárbara en Zarautz, etc.), edificios civiles de interés histórico (palacios solariegos, caseríos, torres fortificadas, etc.), museos (Guggenheim en Bilbao, Zuloaga en Zumaia, etc.) y otros elementos singulares, entre los que sobresale el Puente de Bizkaia en Portugalete (declarado Patrimonio de la Humanidad por la UNESCO en el año 2006). Ello suma unos 87 Bienes de Interés Cultural.

\section{EQUIPAMIENTOS TURÍSTICOS BÁSICOS DE LA RUTA NORTE}

El Camino de Santiago, al igual que cualquier producto turístico, requiere de una estructura organizada en torno - al menos - una oferta de hospedaje y una red de puntos de información que, conjuntamente, ofrezcan al usuario los servicios básicos mínimos para el desarrollo de la actividad turística. El tejido hostelero analizado en el marco de este trabajo se circunscribe a la oferta de restauración y alojamiento en la que se ha constatado previamente la presencia de turistas y/o peregrinos relacionados con el Camino del Norte. Por su parte, la infraestructura de puntos que proporcionan información sobre él la conforma la red de Oficinas de Turismo localizadas en los municipios por los que pasa la ruta jacobea.

\section{La red de alojamientos privados y públicos y los servicios de restauración}

Tradicionalmente, el albergue ha sido la modalidad de alojamiento más utilizada pero se ha constatado que, en ocasiones, la inexistencia o escasez de este servicio en ciertos lugares ha incitado a los peregrinos a elegir otras alternativas tales como campings, agroturismos, hostales, pensiones y hoteles. 
El número de plazas de alojamiento en albergues varía considerablemente a lo largo del año. Así, por ejemplo, en el 2009 se registró un máximo de 1.110 plazas en época estival distribuidas en 23 establecimientos, mientras que el mínimo se alcanzó en invierno cuando se contabilizaron 657 plazas repartidas en 12 establecimientos. Esto obedece a dos motivos: por un lado, a que algunos de los albergues permanecen cerrados durante buena parte del año y, por otro, a que muchos de ellos ofertan un número más elevado de plazas en verano, esto es, cuando se registra una mayor demanda. Los albergues se gestionan según tres modalidades diferentes: privada (representa el 30\% del total de este tipo de establecimientos y el $19 \%$ del número máximo de plazas anual), pública (el 26\% de los establecimientos y el $53 \%$ de las plazas) y «especial» o dependiente de las Asociaciones de Amigos del Camino de Santiago (el $43 \%$ de los establecimientos y el $27 \%$ de las plazas). El número medio de plazas por albergue asciende a 48, siendo muy superior en los de gestión pública que llega hasta las 98 plazas. Los albergues administrados por las Asociaciones de Amigos del Camino de Santiago y por instituciones religiosas (santuarios, monasterios, etc.) resultan ser los más numerosos y también los más demandados por los peregrinos, en razón de su bajo coste (sólo piden donativos) y de su dedicación exclusiva al fenómeno del Camino, lo cual les permite proporcionar información y servicios más específicos (lavaderos, lavadoras, información del Camino y sellado de la credencial). Hay que decir que los locales donde se sitúan los primeros han sido, en todos los casos, cedidos por distintas administraciones públicas. Por lo que se refiere a los albergues privados se ha confirmado que algunos de ellos acogen exclusivamente a peregrinos, mientras que otros están abiertos a cualquier tipo de usuario. Su emplazamiento posee a menudo un carácter estratégico en tanto en cuanto habitualmente se localizan en núcleos de población que carecen de una oferta de albergues gratuitos. Finalmente, todos los albergues públicos se hallan gestionados por las administraciones locales o provinciales y su oferta está dirigida a cualquier perfil de demanda, si bien la mayoría de sus plazas son cubiertas fundamentalmente por colectivos escolares o grupos de jóvenes, de suerte que queda muy reducido el uso por parte de los peregrinos.

Otro tipo de establecimientos de alojamiento, tales como campings, agroturismos, hoteles, hostales y pensiones, hospedan también a personas que realizan el Camino, a veces, reservando un número especifico de plazas expresamente para este colectivo e incluyendo ofertas especiales. Sin embargo, se observa que, ciertamente, son muy pocas las empresas de alojamiento de esta naturaleza que promocionan y se incorporan de forma significativa al producto turístico «Camino de Santiago».

Casi todos los responsables de establecimientos de alojamiento encuestados consideran que la existencia de la ruta jacobea ha incidido, en mayor o menor grado, en su actividad y lo ha hecho en distintas facetas de la misma y en sentido positivo (incremento del número de ventas y empleados, más variedad de productos, etc.). Se reconoce que el Año Jacobeo del 2004 constituyó un claro punto de inflexión a este respecto siendo también el 2007 un año relevante debido a la puesta en marcha de un número destacado de establecimientos. Un ascenso que eso sí- el $50 \%$ de ellos ha definido como moderado y el $23 \%$ como fuerte. Pese a estos datos positivos, únicamente el $34 \%$ de los encuestados ha introducido algún cambio en su estrategia a raíz del auge del Camino, creando nuevos productos o mejorando los ya existentes. Todo ello pone de relieve que quizás la incidencia del Camino de Santiago en la actividad del conjunto de estas empresas no sea tan importante como cabría pensar en un principio. 
Atendiendo a los beneficios económicos obtenidos, en 9 de cada 10 establecimientos de alojamiento el gasto medio dejado por un peregrino no alcanza los 30 euros/día de media, lo cual no obsta para que el $57 \%$ de las empresas encuestadas considere que el Camino de Santiago supone un producto turístico rentable para ellas. Asimismo, el $73 \%$ del conjunto de establecimientos encuestados considera que el Camino ha sido un factor de dinamización en su localidad, generando mayor actividad económica y, en algunos casos, empleo.

Por su parte, el colectivo de empresas dedicadas a la restauración constituye una oferta complementaria a la red de alojamientos y lo componen principalmente restaurantes, bares y cafeterías. Debido a las características particulares de este turismo en ruta se ha constatado que los peregrinos y turistas, habitualmente, realizan los desayunos en bares y cafeterías de los puntos de partida, los almuerzos abasteciéndose en tiendas de alimentación durante el transcurso de las etapas, y las cenas en restaurantes y bares ubicados en los lugares de destino. De este modo, el $60 \%$ de los establecimientos de restauración encuestados efectúa algún tipo de oferta para los peregrinos, la cual suele consistir en un menú ad hoc de alto valor energético. Estos productos específicos se han incorporado recientemente a la oferta turística del Camino y, atendiendo a los resultados, han logrado una buena acogida por parte de la demanda.

\section{Las Oficinas de Turismo}

La infraestructura de puntos de información sobre el Camino Norte de Santiago la componen esencialmente la red de Oficinas de Turismo y la Asociación de Amigos del Camino de Gipuzkoa en su delegación de Txingudi, ubicada en Irún. En este último centro, principal punto de entrada de la ruta en el territorio vasco, numerosos peregrinos recogen sus credenciales y se informan sobre diversos temas relacionados con el viaje que se disponen a emprender. Cabe señalar que el servicio que esta institución ofrece responde a un trabajo voluntario desarrollado por una serie de personas de manera altruista.

Por su parte, las Oficinas de Turismo - todas ellas de carácter público, bien municipal o comarcal - proporcionan a los visitantes información sobre la ruta jacobea, al tiempo que la promocionan como producto turístico. Ocho de las nueve oficinas encuestadas llevan abiertas más de 5 años, cuentan con buena accesibilidad (más de las tres cuartas partes de ellas se localizan en los cascos históricos de los núcleos de población o bien en las proximidades del Camino) y se encuentran bien señalizadas, pese a lo cual el $30 \%$ de los responsables de las mismas opina que podría mejorarse este último aspecto. Como cabía esperar, su personal está profesionalizado y suele asistir a cursos de cualificación fundamentalmente orientados al aprendizaje de idiomas, T.I.C. y atención al cliente. Aunque casi el 90\% de las oficinas abre todos los días de la semana, en horario de mañana y tarde, y el $10 \%$ restante al menos 4 días, poseen un carácter estacional ya que únicamente el $22 \%$ de ellas da servicio durante todo el año. En cuanto al volumen de visitas que acogen, hay que reconocer que sólo una pequeña proporción de ellas está relacionada con el Camino de Santiago (en las dos terceras partes de las oficinas los peregrinos representan menos del $5 \%$ del número total de las visitas). La mitad de las consultas a este respecto son efectuadas por extranjeros, prioritariamente, de nacionalidad alemana y francesa. El periodo estival registra la mayor demanda en todos los casos, excepto en la Oficina de Turismo de Pasaia cuya mayor concentración en invierno y 
primavera (de enero a mayo) obedece a que estas son las épocas esenciales para uno de sus principales señuelos turísticos: las sidrerías. Eso sí, prácticamente en todas las oficinas se ha detectado un incremento del número de consultas relacionadas con el Camino de Santiago durante la última década, un ascenso que el $62 \%$ de ellas califica de fuerte y el $38 \%$ de moderado pero paulatino. Atendiendo a las perspectivas de futuro, más de las tres cuartas partes de las oficinas mantiene esperanzas de crecimiento de cara a los próximos años, y como acicate para que dicha esperanza se confirme y prosiga la tendencia ascendente, un tercio ha recibido por parte de la administración pública algún tipo de ayuda destinada a la promoción de este producto turístico.

\section{BREVE CARACTERIZACIÓN DE LA DEMANDA EXISTENTE. LOS PEREGRINOS EXTRANJE- ROS}

Tal y como se ha señalado, el análisis del flujo de viajeros o - expresado de otro modode la demanda de este producto turístico se ha llevado a cabo a partir del tratamiento, primero, y del análisis, después, de los resultados obtenidos en 100 encuestas realizadas a peregrinos extranjeros. Ello ha permitido la identificación de diferentes perfiles y la disección de sus rasgos más destacados atendiendo a aspectos variados (procedencia, preparación del viaje, motivaciones y expectativas, valoración, etc.).

\section{Perfil de los viajeros}

Como suele ser habitual en estudios de esta naturaleza, antes que nada, se ha caracterizado el perfil de estos viajeros según su edad, sexo y nivel socioeconómico. Para ello se ha realizado, en base a estos elementos, una agrupación en conglomerados mediante un análisis cluster, lo cual ha permitido definir dos tipos de perfiles. Al primero, pertenecen 58 peregrinos que, a grandes rasgos, se distribuyen equitativamente atendiendo al sexo, cuentan con una edad media de en torno a 49 años, poseen un nivel de estudios más bien alto (en un 60 $\%$ de casos de carácter universitario), se encuentran en la actualidad trabajando (65\%) o son jubilados (20\%), y gozan de una situación económica media-alta (96\%). El segundo de ellos aglutina a 34 individuos con una edad media más baja, cercana a los 27 años, una presencia algo mayor de mujeres (18 frente a 16), un nivel de estudios alto y unos ingresos bajos o muy bajos debido a que, en las tres quintas partes de los casos, aún se encuentran en periodo de formación.

Otra de las cuestiones de indudable interés radica en conocer la procedencia de los viajeros, en tanto en cuanto dicho conocimiento permite evaluar, por ejemplo, el grado de atracción y de proyección de los distintos recursos y productos turísticos. Tal y como puede observarse en la Fig. 2, el $82 \%$ de todos los encuestados reside en Europa, sobre todo, en Alemania (25\%), Francia (21\%), países alpinos (Austria y Suiza en conjunto representan el $11 \%$ ) e Italia (8\%). A ellos se suman los procedentes de Europa del Este quienes - a pesar de contar con una tradición menor vinculada a la ruta jacobea - han ido aumentando su presencia en los últimos años (7\%), liderados por Polonia. Por lo que respecta al resto del mundo, sobresale la alta participación relativa de los norteamericanos al representar nada menos que el $16 \%$ del total de encuestados. Aproximadamente las tres cuartas partes de los 
peregrinos extranjeros ha viajado ya en alguna otra ocasión a España, cuatro de cada diez repiten la experiencia jacobea, y por encima de las dos quintas partes de éstos últimos lo han hecho más de una vez, lo cual constituye una indudable prueba de fidelidad al Camino de Santiago. Las razones por las que repiten son variadas, pero destaca la intención de conocer otro trazado diferente a los ya efectuados con anterioridad (15\%), entre los cuales con frecuencia se encuentra el Camino Francés $(90 \%)$. Se ha comprobado que la principal vía de difusión de este fenómeno turístico-cultural consiste en el «boca a boca», de suerte que el $58 \%$ de los peregrinos reconoce haberse enterado de la existencia de esta ruta a través de familiares y amigos. Como cabía esperar, un canal también habitual es Internet (27 respuestas) y, evidentemente, la propia experiencia o contacto previo con otras rutas del Camino (30 respuestas).

PROCEDENCIA DE LOS PEREGRINOS EXTRANJEROS

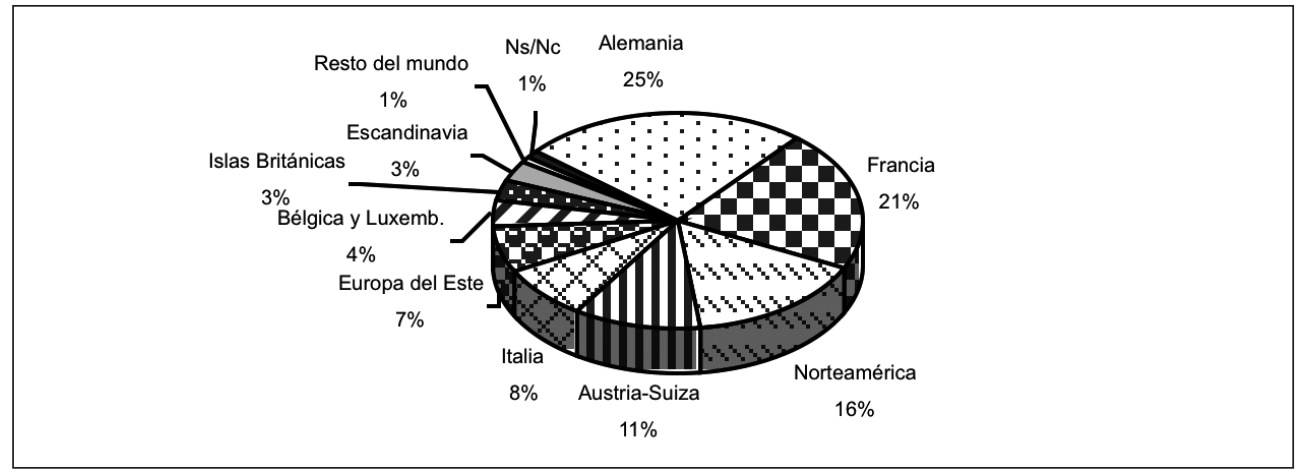

Fuente: Elaboración propia.

\section{Preparación y características del viaje}

En cuanto al medio empleado para realizar el itinerario hay que decir que casi la totalidad de los peregrinos extranjeros lo hace a pie y, sólo en un pequeño porcentaje, utilizando bicicleta (95\% y 5\% respectivamente). El menor peso de esta última forma de transporte en comparación, por ejemplo, con el que adquiere en el Camino Francés es acorde con la orografía de la ruta norte y, particularmente, con sus fuertes pendientes (según la Oficina del Peregrino de Santiago de Compostela, el porcentaje de peregrinos procedentes de todos los Caminos desplazados en bicicleta ha rondado durante los últimos años el 12\%). Por otra parte, se observa que casi la mitad de los peregrinos lleva a cabo el Camino en solitario, el $28 \%$ en pareja o en familia, y el $23 \%$ con amigos. Por lo que se refiere al número de días destinados al viaje, 3 de cada 10 encuestados desconoce el tiempo que va a invertir en su ruta, lo cual pone en evidencia el protagonismo de la improvisación en el comportamiento de muchos peregrinos, que van planificando su ruta «día a día». En todo caso, una cuarta parte de ellos estima que dedicará entre 4 y 6 semanas para el viaje, un $23 \%$ de 2 a 4 semanas y el $16 \%$ entre una y dos semanas (véase Fig. 3). También resulta significativo el hecho de que algunos 
peregrinos (un 4\%) que siguen rutas transeuropeas reserven periodos superiores a dos meses. A la hora de preparar el viaje, casi todos (más concretamente, el 92\%) han buscado información a través de Internet ( 71 respuestas) y de guías especializadas (57 respuestas). Otras vías empleadas para el mismo fin han sido los reportajes televisivos (11) y los folletos turísticos (10). En otro orden de cosas, más de la mitad de los peregrinos ha organizado el viaje por su cuenta pero, con reserva de transporte para desplazarse al punto de partida de la ruta de peregrinación; junto a ellos, aproximadamente una tercera parte lo ha hecho sin realizar reserva alguna. Así pues, se constata el insignificante papel representado por las tradicionales agencias de viaje a este respecto.

NÚMERO DE DÍAS DESTINADOS AL VIAJE

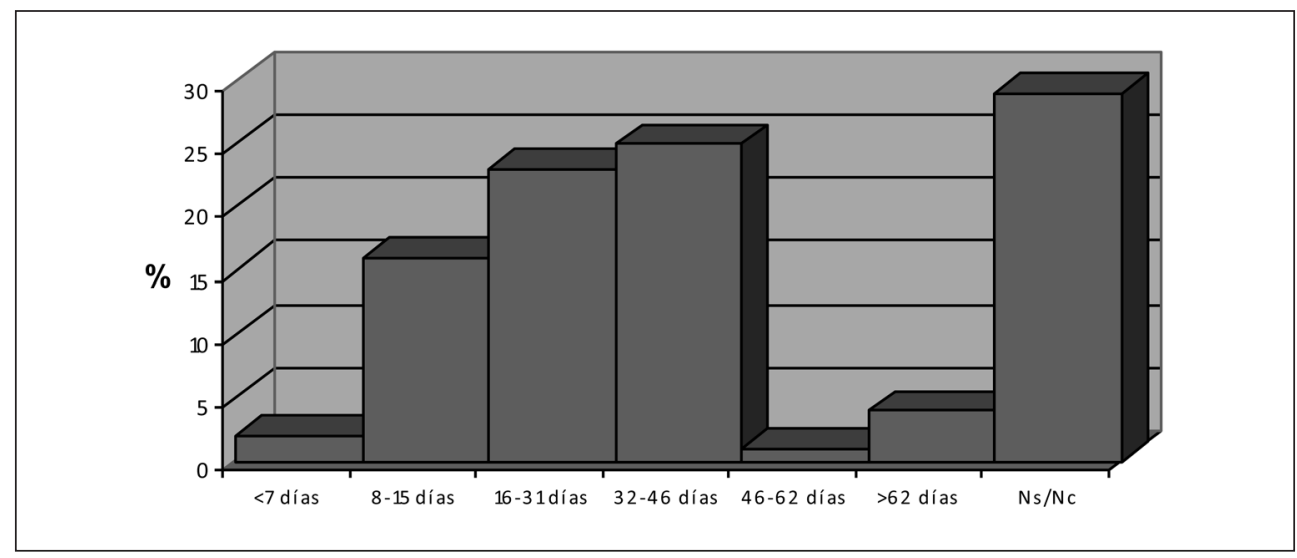

Fuente: Elaboración propia.

Analizados los preparativos del viaje, procede conocer, a continuación, los lugares desde donde parten los peregrinos en su ruta compostelana (Fig. 4). En este sentido, Irún se erige como principal punto de inicio, elegido como tal por la mitad de los encuestados. Otros lugares alternativos de comienzo son Donostia/San Sebastián (en el 13\% de los casos), la Costa Labortana (el 11\%) y Bilbao (el 9\%). Particularmente significativo resulta comprobar que hay peregrinos (alrededor de un $6 \%$ ) que, tras iniciar su ruta en SaintJean-Pied-de-Port/Roncesvalles, deciden abandonar este Camino Francés - habitualmente saturado - y continuar su viaje siguiendo el Camino del Norte. La localización estratégica de Irún, como puerta de entrada a España, y su buena comunicación ferroviaria con el resto del continente europeo son factores que explican la utilización del tren como principal medio de transporte para llegar a este principio de ruta (así ha sucedido en el $43 \%$ de los casos). Con la misma finalidad, un $17 \%$ de los peregrinos emplea autobuses de línea regular, mientras que el $15 \%$ recurre al avión, aterrizando en los cercanos aeropuertos de Biarritz-Anglet-Bayonne y Loiu (Bilbao). 
Figura 4

LUGAR DE INICIO DE LA RUTA NORTE DEL CAMINO DE SANTIAGO

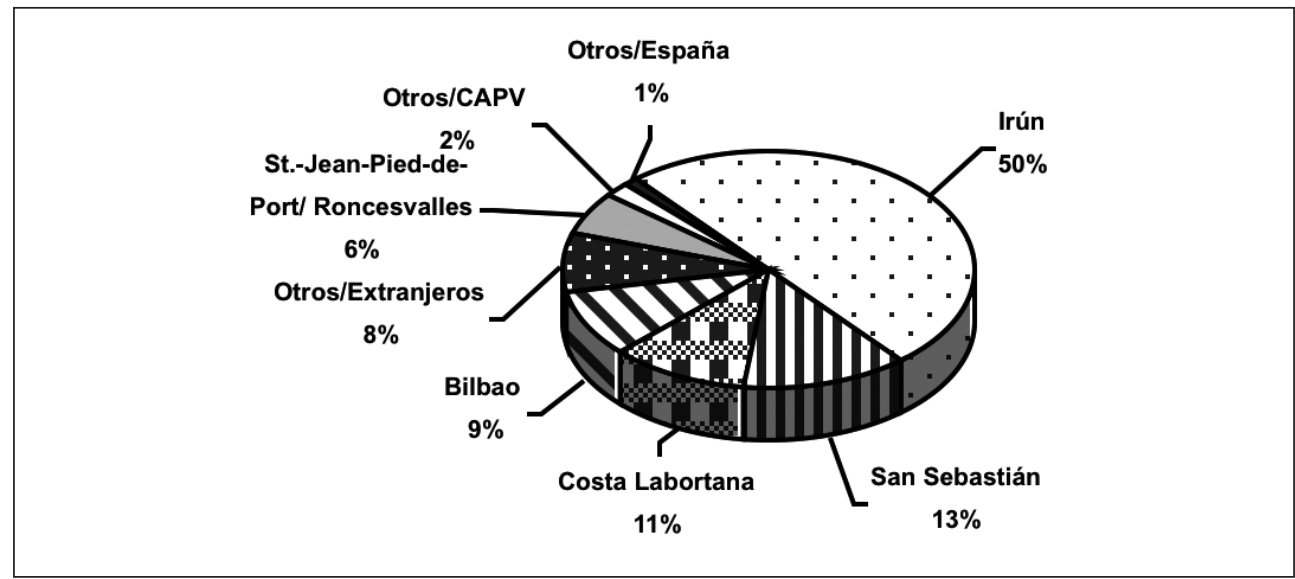

Fuente: Elaboración propia.

En otro orden de cosas, se ha comentado ya que los albergues constituyen la principal modalidad de alojamiento utilizada por los peregrinos, tal y como se pone de manifiesto en los siguientes datos: 9 de cada 10 encuestados han pernoctado en alguno de carácter público y 4 de cada 10 en uno privado. Las principales razones aducidas para ello son, por un lado, de índole económica, ya que el albergue resulta ser la opción más barata, y por otro lado, ideológica, puesto que el $31 \%$ de los encuestados entiende que un verdadero peregrino debe hospedarse así. No obstante, otros establecimientos tales como hoteles, hostales, campings y casas rurales no quedan al margen de esta demanda, generalmente, por la mayor comodidad que ofrecen. En cuanto a los servicios de restauración, 79 turistas confiesan haber comido en cafeterías o bares y 41 en restaurantes. Sin embargo, debido a motivos económicos así como

Figura 5

MODALIDADES DE ALOJAMIENTO UTILIZADAS POR LOS PEREGRINOS EXTRANJEROS

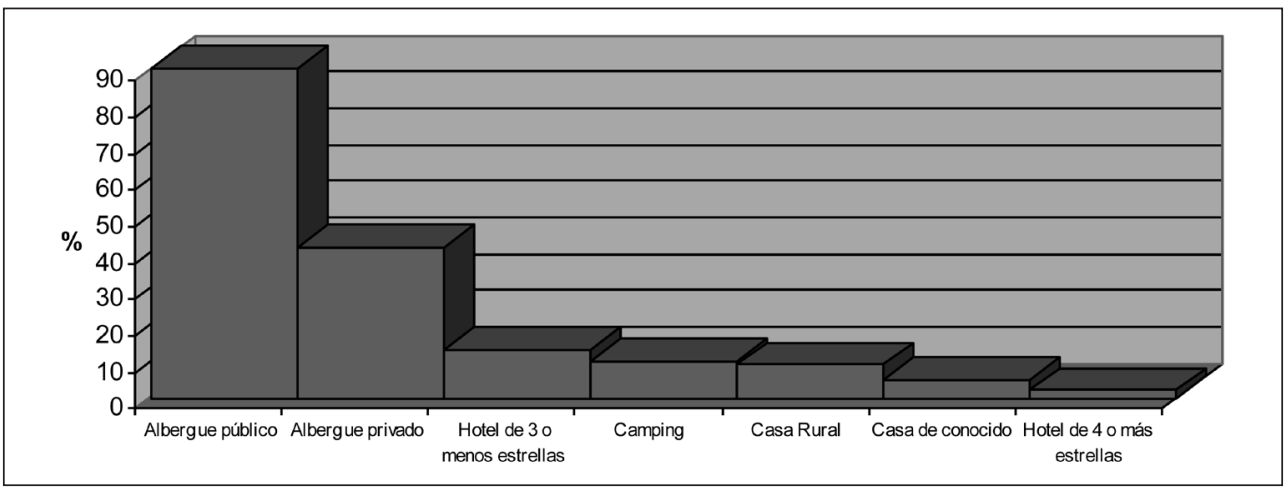

Fuente: Elaboración propia. 
a las características de la ruta, 63 peregrinos han comprado alimentos en supermercados o tiendas y 41 han cocinado en albergues.

\section{Motivaciones y expectativas}

Todo viaje despierta en el turista una serie de expectativas e imágenes de la experiencia a la que se va a someter, fruto de la formación e información recibida así como de las motivaciones previas. Teniendo en cuenta las distintas facetas del Camino de Santiago, como modalidad turística, religiosa y cultural, el análisis de dichas cuestiones reviste un particular interés merced a su diversidad. Hay que ser conscientes — eso sí- de la imprecisión que siempre entraña generalizar sobre las razones que impulsan a miles de personas a emprender un viaje de peregrinación, máxime cuando, a menudo, éstas se hallan entremezcladas incluso en cada persona. Atendiendo a las respuestas obtenidas el $26 \%$ de los 100 peregrinos encuestados busca obtener una experiencia personal o espiritual en el transcurso de la ruta mientras que el $14 \%$ pretende divertirse. Sin embargo, más de la mitad de ellos (concretamente, el $54 \%$ ) no tiene claras sus expectativas, por lo que puede decirse que se enfrentan al viaje con una actitud abierta y aventurera. Para los viajeros, los principales motivos de atracción de esta ruta norte frente a otras residen en el disfrute del paisaje y del medio natural (resaltados por 75 peregrinos), lo cual le otorga un carácter singular y establece una diferencia respecto al Camino Francés, donde el disfrute del patrimonio histórico-artístico constituye el elemento primordial. Hay que señalar que este último aspecto ocupa en la ruta costera el tercer puesto en cuento a preferencias (36 respuestas). Asimismo se advierte que ciertas motivaciones secularmente vinculadas al Camino, tales como la espiritualidad, el reforzamiento personal, la reflexión y la religión, siguen siendo factores clave, de ahí que figuren entre los más relevantes para 83 peregrinos. La ruta jacobea representa para muchos la oportunidad de realizar un viaje, no sólo por paisajes diversos, sino también de profundización interior.

Figura 6

MOTIVACIONES QUE INCITANA REALIZAR EL CAMINO DE SANTIAGO

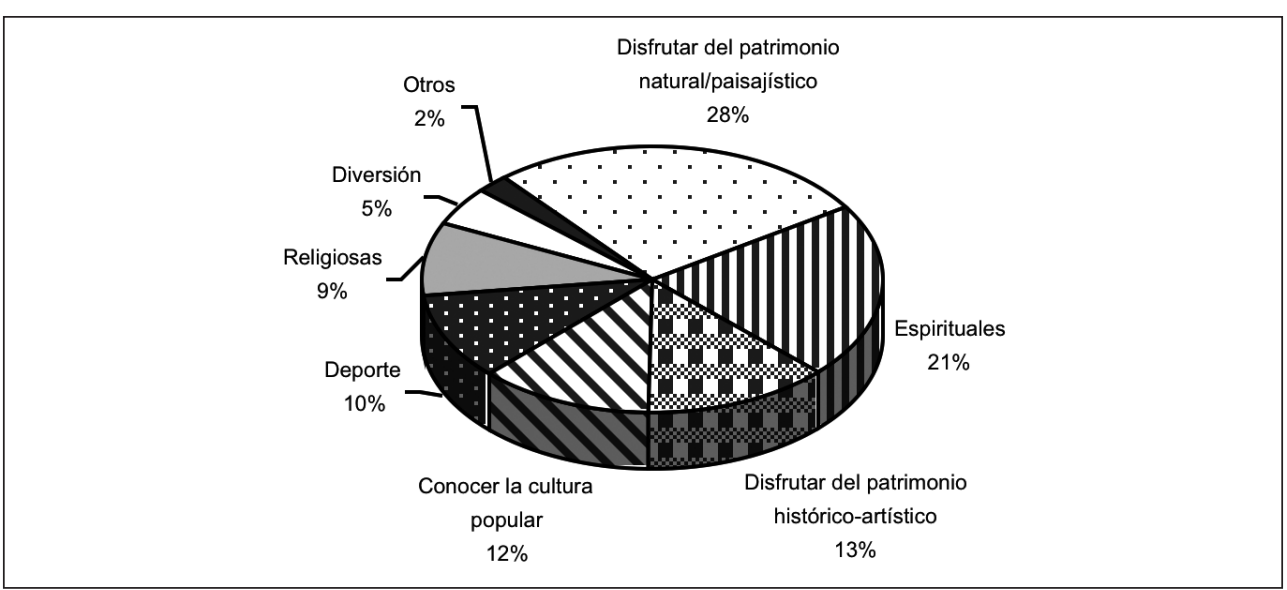

Fuente: Elaboración propia. 


\section{VALORACIÓN DEL CAMINO DE SANTIAGO POR PARTE DE LOS PRINCIPALES COLECTI- VOS IMPLICADOS}

El conocimiento de la valoración que los usuarios y agentes sociales e institucionales implicados hacen de los distintos elementos que componen un fenómeno (en este caso, un producto turístico y un itinerario religioso-cultural) adquiere una importancia crucial, en tanto en cuanto permite efectuar un diagnóstico global de su estado actual y de sus perspectivas futuras. Asimismo esa valoración realizada desde variadas perspectivas resulta de gran ayuda con vistas a implementar las correcciones necesarias que eviten el deterioro patrimonial y ajusten la oferta a las exigencias de la demanda en el marco de los parámetros de sostenibilidad.

\section{Valoración y grado de satisfacción de los peregrinos extranjeros}

En el contexto de esta ruta norte, los aspectos más valorados por parte de los viajeros han sido, por orden de importancia, su patrimonio natural y paisajístico, la experiencia personal adquirida al realizarla, y su patrimonio cultural e histórico-arquitectónico. Por el contrario, como elementos negativos destacan la notable exigencia física que requiere efectuarla, debido a su accidentado trazado, y, en suma, el sufrimiento corporal al que se ven sometidos los caminantes a lo largo de las etapas.

También se advierte que la insuficiencia de alojamiento en albergues sobresale como debilidad, tal y como lo confirma el hecho de que el $69 \%$ de los encuestados considere que deba llevarse a cabo, al menos, algún tipo de mejora al respecto. Asimismo se han evidenciado problemas en la señalización de la ruta y carencias relativas a los puntos de información (subrayados, respectivamente, por el $63 \%$ y el $60 \%$ de los peregrinos). Pese a todo, el $79 \%$ de ellos opina que el grado de mejora global del Camino debe ser escaso, frente a tan solo un $4 \%$ que piensa que son necesarias actuaciones relevantes. Todo ello induce a pensar que el estado actual de este producto turístico - aunque requiera correcciones - pueda calificarse, en términos generales, de bueno. Otra de las cuestiones sometidas a evaluación ha sido la calidad de los albergues; tras dicho examen se aprecia que tanto el grado de confort como la limpieza e higiene de todos ellos han obtenido una valoración positiva, siendo, en cualquier caso, el servicio y la atención prestada al visitante el aspecto mejor considerado.

Como ya se ha comentado, una de las principales vías de conocimiento de la ruta norte es la información proporcionada al respecto por personas allegadas, razón por la cual el nivel de satisfacción alcanzado por cada usuario adquiere una gran relevancia para su promoción. Así resultan sumamente reveladoras las respuestas dadas por los peregrinos a preguntas acerca de la intención de repetir la experiencia turística o de recomendarla a otras personas. Los resultados obtenidos en las encuestas pueden parecer, en principio, paradójicos, puesto que si bien el $77 \%$ de las personas consultadas afirma que volvería hacer el Camino, un $60 \%$ no recomendaría este viaje, lo cual quizás obedezca a la dureza de esta ruta y al esfuerzo físico requerido para terminarla - tal vez, poco aconsejable - . A la pregunta de si la experiencia cubría o no sus expectativas un $29 \%$ ha contestado que estaba resultando mejor de lo esperado, frente a un escaso $9 \%$ que opinaba lo contrario. Ahora bien, es preciso tomar estas respuestas con cautela, sobre todo las realizadas en las primeras etapas de la ruta, dado que en 
estos casos la experiencia acumulada por los viajeros resulta demasiado breve para efectuar una valoración ajustada. Pese a todo, se ha constatado que para el $83 \%$ de los peregrinos extranjeros encuestados su nivel de satisfacción global es medio-alto.

\section{Valoración de los responsables de instituciones y entidades culturales}

Las instituciones juegan un papel primordial en la puesta en valor de los recursos turísticos, hecho que, obviamente, también se refleja en la ruta Norte del Camino de Santiago a su paso por la Comunidad Autónoma del País Vasco. Debido a las limitaciones de espacio del presente artículo va a realizarse un breve comentario centrado en dos tipos de organismos: las Oficinas de Turismo y las Asociaciones de Amigos del Camino de Santiago.

\subsection{Oficinas de Turismo}

Se han consultado para este trabajo todas las Oficinas de Turismo situadas a lo largo de la ruta Norte en su tramo vasco (esto es, 9 oficinas), con la excepción de las ubicadas en Bilbao y Donostia/San Sebastián, ciudades donde la incidencia del Camino en términos de flujos turísticos resulta muy anecdótica. La imagen global que poseen de este ramal de la ruta jacobea puede descomponerse en los siguientes rasgos positivos y negativos: existe falta de organización y carencia de infraestructuras así como un conflicto entre los distintos perfiles de viajeros pero, indudablemente, adquiere un alto valor como experiencia personal, posee un gran atractivo paisajístico y goza ya de un nivel de proyección internacional, el cual se hace patente en una notable afluencia de peregrinos extranjeros. Asimismo la ruta norte representa una gran oportunidad como trazado alternativo al Camino Francés y como opción de ocio vinculada al turismo deportivo, cultural, etc. Por su parte, siete de las nueve oficinas encuestadas consideran que hay expectativas de crecimiento para el producto turístico «Camino de Santiago», siempre y cuando esta ruta mejore en cuestiones tales como la organización de la oferta y se incremente el apoyo institucional.

\subsection{Asociaciones de Amigos del Camino de Santiago}

Las Asociaciones de Amigos del Camino de Santiago son organismos sin ánimo de lucro, formados por voluntariado, cuyo principal fin consiste en «facilitar información y apoyo a peregrinos, viajeros y otras personas o entidades interesadas en el Camino de Santiago» (Federación Española de Asociaciones de Amigos del Camino de Santiago, 2006). En el marco de este estudio se han mantenido entrevistas con cinco representantes de las distintas asociaciones provinciales de Álava, Guipúzcoa y Vizcaya, así como de algunas delegaciones comarcales guipuzcoanas, siendo éste último el único territorio que alberga una organización jerarquizada geográficamente. La visión que este colectivo tiene sobre el Camino de Santiago resulta particularmente interesante ya que se vincula al significado histórico y tradicional de la ruta jacobea. A grandes rasgos, poseen una imagen positiva del Camino y, a su entender, merece ser resaltada la experiencia personal que se obtiene en el transcurso del viaje. Consideran que, paulatinamente, se está produciendo una sustitución de las motivaciones religiosas por otras de carácter más turístico y también que, el Camino Norte, representa 
la oportunidad de convertirse en una ruta alternativa al colapsado Camino Francés. Todas las personas entrevistadas coinciden en afirmar que el futuro de esta ruta es de crecimiento en cuanto al número de viajeros. Sin embargo, como contrapartida a este escenario, resaltan la existencia de problemas organizativos y las carencias en infraestructuras.

\section{Valoración de las Agencias de Viajes}

Atendiendo al trabajo efectuado, cuatro agencias de viajes de la Comunidad Autónoma del País Vasco ofertan y comercializan el «Camino de Santiago» como producto turístico, en un caso, desde 1992 y, en el resto, con posterioridad al año 2000. Junto a ellas, algunas otras han manifestado que, en ciertas ocasiones, se han encargado de buscar y contratar alojamiento para peregrinos del Camino de Santiago si así lo han solicitado. Ante esto conviene recordar que la lógica señala que la ruta norte del Camino de Santiago sea comercializada en agencias de viajes de otros territorios. Asimismo - como cabía esperar - buena parte de las agencias receptivas consultadas han declarado que sus clientes son siempre agencias extranjeras que, en cada caso, realizan las peticiones pertinentes, por lo que el producto turístico se realiza a medida; al hilo de ello, reconocen que a veces sí han organizado el programa «Camino de Santiago». Las empresas que comercializan el producto también suelen brindar itinerarios «a la carta», aunque lo frecuente son viajes de 7 u 8 días, y sus paquetes turísticos pueden incluir reservas de alojamiento y restaurantes, coche de alquiler o transporte público, visitas guiadas, etc. Los principales colectivos demandantes los constituyen clientes individuales, familias o pequeños grupos, interesados en cultura y naturaleza y, algunos, con intereses religiosos, con un predominio - atendiendo a la edad - de mayores de 31 años y de procedencia, a menudo, extranjera (Alemania, Francia e Italia). En líneas generales, han detectado un ascenso de la demanda, gracias a las personas que buscan zonas españolas «más auténticas» y menos comerciales, y, en concordancia con ello, se muestran optimistas en cuanto a las perspectivas de futuro de este Camino.

\section{Valoración de la Administración Turística Regional}

La Administración Turística Regional promociona Caminos de Santiago en Euskadi, entendido como una suma de productos y servicios «tematizados» en torno a la ruta jacobea, con una doble intención: convertirlo en un motor de desarrollo para las economías locales y contribuir a reforzar la competitividad del turismo vasco frente a otros destinos con características similares. Se comercializa en aquellos países donde la C.A.P.V. realiza acciones de promoción de manera directa, o bien a través de la España Verde o del Protocolo de Cooperación establecido con Turespaña y otras Comunidades Autónomas que participan del Camino (Galicia, Principado de Asturias, Cantabria, La Rioja, Aragón, Castilla y León y Navarra). Las conversaciones mantenidas con expertos ponen de relieve algunas de las debilidades detectadas en estos últimos años en relación con dicho producto turístico: ausencia de coordinación entre las intervenciones implementadas por el amplio espectro de agentes turísticos y no turísticos que intervienen en el mismo; falta de reconocimiento y conocimiento en el seno del País Vasco sobre las rutas jacobeas; y no asociación del territorio vasco con el Camino de Santiago, en el conjunto de mercados turísticos. Por lo que se refiere a su 
incidencia económica y social reconocen que el Camino no ha generado un incremento de la oferta hotelera, si bien ha supuesto un aumento de los albergues de peregrinos, unos alojamientos que, a efectos administrativos, no son considerados «turísticos» en el País Vasco; ha repercutido levemente en un ascenso de los niveles de empleo pero casi en su totalidad de carácter temporal; ha propiciado ciertas mejoras en la rehabilitación y conservación del patrimonio, en las infraestructuras y en los equipamientos; y, al decir de algunos alcaldes y concejales, los peregrinos - como consumidores que han de satisfacer unas necesidades básicas - contribuyen en grados diversos al desarrollo económico de los municipios por los que pasan. Con el objeto de promocionar el Camino de Santiago en Euskadi y, en última instancia, de «poner en valor su importante potencial económico, turístico y medio ambiental» el Gobierno Vasco está elaborando un Plan Director, que va a ser presentado en el año 2010. Asimismo se pretende que, tras la aprobación por el Consejo del Patrimonio Histórico Español de la correspondiente candidatura, la UNESCO declare en el año 2012 los Caminos de Santiago del Norte de España como Patrimonio Mundial (una catalogación que en el País Vasco sólo ostentan el Puente de Bizkaia y las cuevas de Ekain, Santimamiñe y Atzerri).

\section{DISTINTAS VISIONES Y PLANTEAMIENTOS DE GESTIÓN DEL CAMINO DE SANTIAGO}

La singularidad del Camino de Santiago motiva que este sea un fenómeno de naturaleza compleja interpretable desde diferentes perspectivas, tantas como - al menos - perfiles de viajeros participan en él. Cada uno de esos perfiles se corresponde con un uso determinado, de forma que en un mismo ámbito pueden confluir numerosas actividades, relacionadas o no, con el hecho turístico. En efecto, el Camino ha sido tradicionalmente un espacio religioso de peregrinaje, pero, cada vez más, un itinerario histórico, cultural y deportivo. Al hilo de ello, el amplio abanico de impresiones recogidas en este trabajo ha sido clasificado en tres grandes grupos de opinión.

\section{El Camino de Santiago entendido como un espacio de peregrinaje religioso/personal}

Esta concepción se halla encabezada principalmente por las Asociaciones de Amigos del Camino de Santiago. Tienen una visión tradicional del Camino, entendiéndolo como un fenómeno colectivo, pero de naturaleza individual. Para ellos, las motivaciones que inducen a los peregrinos a emprenderlo son esencialmente de índole religiosa o espiritual. Desde este punto de vista, el peregrino se revela como una persona que necesita llegar a Santiago para ver recompensadas sus motivaciones, teniendo por delante un largo viaje lleno de dificultades que debe solventar; por ello, existe un sentimiento de compasión hacia él, gracias al cual se le ofrece una serie de servicios de manera solidaria, entre los que sobresale el alojamiento en hospitales de peregrinos. En líneas generales, este grupo de opinión manifiesta un profundo rechazo por la visión de la ruta jacobea como producto turístico, esgrimiendo dos argumentos principales: por un lado, que dicho enfoque adultera el espíritu del Camino y es ajeno a los tradicionales motivos de su existencia y, por otro, que la oferta básica de alojamiento vinculada a los peregrinos se ve saturada por los turistas. En este contexto, los viajeros que realizan la ruta de peregrinación inducidos exclusivamente por razones turísticas son denominados coloquialmente «turigrinos». 


\section{El Camino de Santiago concebido como un producto turístico cultural, deportivo, de la naturaleza, etc.}

Los agentes relacionados con el sector turístico dentro la Comunidad Autónoma del País Vasco interpretan el Camino de Santiago esencialmente como un producto turístico. Este colectivo lo integran fundamentalmente las administraciones públicas (por ejemplo, el Departamento de Industria, Innovación, Comercio y Turismo del Gobierno Vasco y los encargados de los temas turísticos en Diputaciones, comarcas y ayuntamientos) así como empresas privadas vinculadas al sector y ubicadas en torno a la ruta. A su entender, el Camino constituye un producto turístico, un sistema en el que el peregrino es el demandante que busca una oferta turística para satisfacer sus necesidades de ocio y que se desplaza para ello. Eso sí, las motivaciones de estos viajeros componen un amplio espectro que va desde la práctica deportiva, hasta el deleite del patrimonio cultural y natural, el conocimiento de las tradiciones de los lugares por los que pasa o el disfrute de unas vacaciones alternativas. El modelo de gestión según esta manera de entender el Camino debe ajustarse a las leyes del mercado, abarcar las distintas fases de toda cadena turística y, en tanto actividad económica, perseguir la obtención de beneficios a este respecto. De este modo, las competencias de los organismos públicos se encaminan esencialmente a la gestión y organización de las infraestructuras a lo largo del trayecto, así como a las labores de difusión y marketing del producto turístico. Por otro lado, la iniciativa privada que ha sido contemplada en el ámbito de este estudio proporciona, prioritariamente, servicios básicos de alojamiento y manutención y, en menor medida, actividades complementarias, utilizando para ello cauces variados de promoción.

\section{El Camino de Santiago, trazado de convivencia entre turistas y peregrinos}

Ciertas instituciones y empresarios ligados al Camino de Santiago entienden que este es un espacio en el que peregrinos con motivaciones religiosas, espirituales, o de enriquecimiento personal, y turistas con fines de ocio pueden convivir sin generar conflictos de usos si la gestión se efectúa de tal manera que todas las opciones sean válidas y tengan cabida. Los primeros, precisarán, sobre todo, tener cubiertas sus necesidades básicas de alojamiento y comidas; los segundos, probablemente plantearán mayores y más variadas exigencias en cuanto a cantidad y calidad de servicios. Pero, más que un hándicap y una adulteración, esta pluralidad cabe ser vista como una oportunidad de enriquecimiento para el propio fenómeno del Camino de Santiago. En concordancia con ello, se plantea un modelo de gestión en el que la cooperación y la coordinación resultan imprescindibles. Un ejemplo encontrado de lo que podría denominarse fórmula de gestión «mixta» radica en la labor conjunta llevada a cabo por la Asociación de Amigos del Camino de Santiago de Guipúzcoa — en su delegación comarcal de Deba - y la Oficina municipal de Turismo de la citada localidad, puesto que, a pesar de tener puntos de vista divergentes sobre el Camino, trabajan de forma coordinada. Prueba de ello es que esta oficina, además de ser punto de información, ha pasado a custodiar el hospital de peregrinos existente. 


\section{CONCLUSIONES}

El Camino de Santiago forma parte del patrimonio cultural intangible de excepcional valor, que cuenta con reconocimiento y proyección internacional. Constituye un fenómeno pluridimensional, un espacio de encuentro y convivencia para viajeros con motivaciones muy distintas, y una realidad compleja en tanto en cuanto son varios los Caminos existentes, que atraviesan territorios de rasgos dispares para llegar a un mismo destino. Tanto nuestro diagnóstico sobre las características e incidencia del Camino Norte en el País Vasco como la valoración efectuada al respecto por distintos colectivos y agentes sociales, han puesto en resalte una serie de oportunidades, amenazas, fortalezas y debilidades.

Entre las primeras, pueden ser destacadas las siguientes: 1) El efecto catalizador que ha demostrado para la promoción de la ruta del Norte el Año Jacobeo 2010 y también su inclusión como uno de los elementos más significativos de la oferta internacional de la «España Verde»; 2) La ocasión de seguir fomentando la cooperación territorial ya iniciada y de que el Camino de Santiago se convierta en un instrumento de cohesión territorial, que favorezca el sentido de pertenencia a un proyecto común entre las sociedades que lo integran, la articulación de mecanismos de coordinación interinstitucional, y el intercambio de experiencias y de buenas prácticas; 3) La oportunidad que presenta la ruta del Norte de convertirse en un producto turístico alternativo al tradicional Camino Francés dirigido, particularmente, a aquellos peregrinos a quienes no les satisface este último debido a su masificación o priorizan aspectos como el paisaje costero en su escala de valores; 4) La posibilidad de que el Camino sea un verdadero instrumento de desarrollo regional y, más concretamente teniendo en cuenta su trazado, de desarrollo rural; 5) El reto de que el Camino constituya una vía jalonada de ventanas hacia el Patrimonio que contribuya al conocimiento y a la toma de conciencia de su valor no sólo por parte de los viajeros sino, antes que nada, por la población local; 6) La oportunidad de implementar fórmulas que propicien que los beneficios generados por el turismo reviertan, de algún modo, en la conservación y puesta en valor del patrimonio, en concordancia con los objetivos establecidos al respecto en la Carta de ICOMOS de Turismo Cultural (ICOMOS, 1999); 7) La excelente oportunidad de marketing territorial; 8) El desafío y la ocasión de que los peregrinos vuelvan más tarde al País Vasco en calidad de turistas, con sus familias o amigos, si la experiencia adquirida es satisfactoria.

Por lo que se refiere a las fortalezas que presenta la Ruta Norte he aquí algunas de las que, a nuestro entender, merecen ser resaltadas: 1) La variada y extraordinaria riqueza paisajística que ofrece la conjunción de costa y montaña, sin duda, un recurso económico, natural, cultural y turístico de gran valor; 2) Su mayor confort térmico en comparación con el Camino Francés para realizar la ruta en época estival que, tal y como se ha constatado en el trabajo, constituye la época de mayor afluencia de peregrinos; 3) Su menor nivel de saturación frente a otras rutas tradicionales, un factor que, según han revelado las encuestas realizadas, es determinante en el grado de satisfacción de muchos peregrinos; 4) La existencia de un relieve intrincado que, para algunos, puede ser entendido como una debilidad por el esfuerzo físico que requiere salvarlo, pero también como una fortaleza en tanto en cuanto ofrece la posibilidad de establecer áreas de descanso en puntos estratégicos desde los que contemplar e interpretar el paisaje; 5) La concienciación por la Administración Pública de la necesidad de encarar la gestión del Camino del Norte, patente en el proceso de elaboración 
de un Plan Director al respecto; 6) La puesta en marcha de algunas actuaciones tales como la creación de un Centro de Interpretación sobre el Camino de Santiago en el País Vasco, ubicado en la costa guipuzcoana (concretamente en Orio), rehabilitando para ello un elemento patrimonial de arquitectura civil: el Palacio Iturriaga.

En cuanto a las principales debilidades que se han puesto de manifiesto a lo largo del estudio destacan las siguientes: 1) Falta de coordinación interinstitucional e intermunicipal, y predominio de iniciativas aisladas que reflejan la ausencia de una planificación integral del Camino Norte; 2) Deficiencias en la señalización y en las infraestructuras a lo largo de la ruta que, en el primer caso, se concretan en la existencia de una señalización «insuficiente, defectuosa y duplicada» y, en el segundo, en el mal estado de las vías, a menudo, por falta de mantenimiento (matorrales, basuras, etc.); 3) Insuficiente oferta de plazas en la red de albergues existente para la demanda detectada; 4) Conflictos de usos y propiedad que, en algunos casos, ha afectado al trazado de la ruta tradicional desviándolo; 5) Ausencia de un plan de adecuación e Interpretación del Patrimonio.

Junto a ellas se cierne la amenaza de repetir el modelo del Camino Francés (en opinión de algunas de las personas encuestadas «saturado y explotado, fundamentalmente, como un negocio») y el riesgo de promocionarlo y difundirlo sin una planificación previa de uso y gestión, que sea vinculante. Esto último quebrantaría la exigencia de protección de un patrimonio que, por su excepcional valor, pertenece a la humanidad en su conjunto.

En concordancia con todo ello, la principal propuesta que aquí se plantea radica en el desarrollo de una planificación integral del Camino Norte desde su inicio, en Irún, hasta su destino, Santiago de Compostela, en la que prevalezca su condición de itinerario cultural especial pero también de patrimonio territorial. En dicho contexto, formulamos las siguientes líneas de actuación: 1) Garantizar la continuidad al esfuerzo de cooperación interterritorial y al trabajo en red; 2) Fomentar las relaciones entre organizaciones públicas y privadas siguiendo en cierto modo, la experiencia iniciada de forma espontánea a escala local, en Deba; 3) Crear un organismo específico encargado de intervenir de modo integral en el Camino; 4) Resolver las deficiencias de señalización, asignando la responsabilidad a un único órgano gestor, así como afianzar la ruta, manteniendo el trazado y revisando las lindes; 5) Garantizar un mínimo de calidad en todos los servicios ofertados a los viajeros y decidir si resulta prioritario fomentar la red de albergues o, más bien, los servicios de alojamiento reglado (casas rurales, agroturismos, etc.), teniendo en cuenta que, lo primero, se ajustaría en mayor grado a las preferencias expresadas por los peregrinos extranjeros encuestados así como al «espíritu del Camino» resaltado por los hospitaleros, mientras que, lo segundo, entroncaría más directamente con la aspiración de que el Camino contribuya al desarrollo rural; 6) Regularizar todo el sistema de alojamiento para peregrinos, de suerte que esté sujeto a normativa; 7) Constituir una red de establecimientos de agroturismos y restauración acogidos a un programa de tarifas especiales para peregrinos; 8) Elaborar un Plan de Interpretación del Patrimonio y crear una serie de áreas de descanso con servicios de fuentes, bancos con mesas y paneles informativos sobre los caracteres y elementos de interés del territorio que se está atravesando; 9) Definir la capacidad de acogida de los distintos tramos del Camino así como de los equipamientos de distinta índole vinculados a él; 10) Desarrollar un aplicación WEB sobre Paisaje y Patrimonio de esta ruta, apta para plataformas móviles 
(teléfonos, PDA, etc.); 11) Proseguir con acciones conjuntas dirigidas a la promoción de las regiones implicadas y a la elaboración de materiales de difusión.

Entre otras muchas cosas, las distintas visiones analizadas han puesto en resalte la conflictiva relación entre Turismo y Patrimonio, claramente expuesta en la siguiente reflexión: «El turismo se desarrolla en un escenario protagonizado básicamente por el sector privado cuyo fin principal es la obtención de beneficios económicos, mientras que el patrimonio cultural se desarrolla en un escenario cuyo protagonista principal es el sector público cuyo fin es obtener beneficios sociales. El liderazgo de ambos sistemas es ejercido por distintos actores que persiguen fines diferentes» (Velasco, 2009). El escollo aumenta cuando además se trata de un itinerario cultural que atraviesa diversas Comunidades Autónomas con competencias transferidas, de un bien de alto contenido simbólico que trasciende fronteras, propuesto para ser catalogado Patrimonio de la Humanidad (con la fuerte proyección turística que ello supone pero también con los requerimientos de conservación que exige), y de una ruta con fuerte trasfondo religioso y espiritual recorrida por viajeros de perfiles heterogéneos.

\section{BIBLIOGRAFÍA}

AUCORT, R. (1990): «Pèlegrins, touristes ou touristes religieux?», Espaces, n 102, 19-21.

EADE, (2002): «Pilgrimage and tourism at Lourdes, France», Annals of Tourism Research, vol. 19 (1), 18-32.

ESTEBE, R. (2002): Turismo y religión. Aproximación a la historia del turismo religioso. Málaga, Servicio de Publicaciones de la Universidad de Málaga.

GERMAIN, A. (2007): «El mercado español de turismo religioso, un sector prometedor para la profesión», Editur, n 2480, 2-6.

GOBIERNO VASCO, DEPARTAMENTO DE INDUSTRIA, COMERCIO Y TURISMO (2008): «I Plan de Marketing de Euskadi, Hor Dago! Plana, 2009-2012», Documentos del Turismo Vasco, $\mathrm{n}^{\circ}$ 18, Vitoria-Gasteiz, Eusko Jaurlaritza-Gobierno Vasco, Servicio de Publicaciones.

GRÉGOIRE, J.Y. y PINGUET, F. (2010): Le Chemin Côtier (Camino del Norte) vers SaintJacques- de Compostelle. Guide pratique du pèlerin. Ibos, Ed. Rando.

ICOMOS (2008): «The Icomos Charter on Cultural Routes, ratified by the 16th General Assembly of ICOMOS, Québec (Canada) on 4 October 2008». Disponible en http:// www.international.icomos.org/quebec2008/charters/cultural_routes/pdf/GA16_Charter_ Cultural_Routes_20081004_FR+EN.pdf

LABORDE-BALEN, L. y ROUSSET, J.P. (2004): Les chemins de Saint-Jacques en Béarn et Pays Basque. Bordeaux, Editions Sud Ouest.

LOIS, R. y SANTOS, X. (1999): «El Camino de Santiago», en La actividad turística española en 1998 (Bote, V., ed.). Madrid, AECIT, 597-603.

MORINIS, A. (1992): «Introduction. The territory of the Anthropolgy of Pilgrimage», en Sacred Journeys. The Anthropology of Pilgrimage. Westport, Greenwood Press, 1-28.

PORCAL GONZALO, $\mathrm{M}^{\mathrm{a}}$.C. (2006): «Turismo cultural, turismo religioso y peregrinaciones en Navarra. Las «Javieradas» como caso de estudio», Cuadernos de Turismo, n ${ }^{\circ} 18,103$ 134. 
PRECEDO LEDO, A. et. al. (2007): «El turismo cultural como factor estratégico de desarrollo: el Camino de Santiago», Estudios Geográficos, vol. LXVIII, nº 262, 205-234.

SANTOS SOLLA, X. (1999): «Mitos y realidades del Xacobeo», Boletín de la Asociación de Geógrafos Españoles, $\mathrm{n}^{\circ}$ 27, 103-117.

SMITH, V.L. (1992): «Introduction. The quest in guest», Annals of Tourism Research, nº 19 (1), 1-17.

TONDRE, F. (2007): El Patrimonio Cultural y los Itinerarios Culturales del Consejo de Europa. Nuevas orientaciones. Caminos hacia la diversidad, puentes entre las comunidades: el patrimonio cultural en las sociedades plurales. Disponible en http://www. redjuderias.org/red/upload/boletin/pdf/BO-08-281.pdf

TURNER, V.W. y TURNER, E. (1978): Image and pilgrimage in Chistian culture. Anthropological perspectives. Nueva York, Columbia University Press.

VELASCO GONZÁLEZ, M. (2009): «Gestión turística del patrimonio cultural: enfoques para un desarrollo sostenible del turismo cultural», Cuadernos de Turismo, n ${ }^{\circ} 23,237$ 254.

VUKONIC, B. (1997): Tourism and religion. Oxford, Ed. Pergamon. 